Ary Serpa Neto

Marcus J. Schultz

Emir Festic

\section{Ventilatory support of patients with sepsis or septic shock in resource-limited settings}

Received: 7 August 2015

Accepted: 20 September 2015

Published online: 28 September 2015

(C) Springer-Verlag Berlin Heidelberg and ESICM 2015

Group members of the 'Sepsis in Resource-limited Settings' group are listed in the online supplement.

For the 'European Society of Intensive Care Medicine (ESICM) Global Intensive Care' working group and the 'Mahidol-Oxford Research Unit' (MORU), Bangkok, Thailand.

Electronic supplementary material The online version of this article (doi:10.1007/s00134-015-4070-0) contains supplementary material, which is available to authorized users.

\section{A. Serpa Neto}

Medical Intensive Care Unit, Hospital Israelita Albert Einstein, São Paulo, Brazil

e-mail: aryserpa@terra.com.br

\section{A. Serpa Neto}

Program of Post-graduation, Research and Innovation, Faculdade de Medicina do ABC, São Paulo, Brazil

\section{A. Serpa Neto · M. J. Schultz \\ Department of Intensive Care, Academic Medical Center, University of Amsterdam, Amsterdam, The Netherlands}

\section{J. Schultz}

Laboratory of Experimental Intensive Care and Anesthesiology (L.E.I.C.A), Academic Medical Center, University of Amsterdam, Amsterdam, The Netherlands

\section{J. Schultz (®)}

Mahidol-Oxford Research Unit (MORU), Faculty of Tropical Medicine, Mahidol University, 420/6 Rajvithi Road, Bangkok 10400, Thailand

e-mail: marcus.j.schultz@gmail.com

E. Festic

Pulmonary and Critical Care Medicine, Mayo Clinic, Jacksonville, FL, USA

e-mail: festic.emir@mayo.edu

\section{Introduction}

Research evidence for ventilatory support recommendations in sepsis and septic shock management has been mainly gathered from investigations in resourcerich settings. Often, it is not practical to directly translate this evidence to resource-limited settings. Indeed, resource-limited intensive care units (ICUs) are frequently restricted in the availability of equipment, laboratory support and skilled staff. We report on a set of pragmatic recommendations for ventilatory support in sepsis and septic shock management in resource-limited settings, built upon two previous sets of guidelines for sepsis management, the most recent Surviving Sepsis Campaign guidelines [1] and the recommendations for sepsis management by the Global Intensive Care Working Group of the ESICM [2], as well as upon an updated literature search and expert opinions [3].

An international team of physicians from resourcerich and -limited settings with hands-on experience in resource-limited ICUs critically appraised a list of questions regarding ventilatory support by partly using the Grading of Recommendations Assessment, Development and Evaluation (GRADE) tools [4] and by reviewing the literature for any additional evidence from resource-limited settings. The quality of evidence was scored from very high (A) to very low (D), and the strength of recommendations was strong (1) or weak (2) considering the indirectness of the evidence, the magnitude of effects, availability and feasibility in resourcelimited ICUs, and safety. In the absence of evidence from resource-limited ICUs, evidence from resource-rich ICUs was adopted after pragmatic, experience-based appraisal. Full scoring details are available in the online supplement. 


\section{Results and recommendations for ventilatory support in resource-limited ICUs}

Although ventilatory support is generally seen as a simple and potentially life-saving intervention, there is increasing evidence for its possible harmful effects. Therefore, besides grading the evidence for general ventilatory settings (ventilation mode, oxygen concentration, tidal volume, positive end-expiratory pressure (PEEP) and recruitment maneuvers), we weighted strategies that might obviate the need for invasive ventilation, or shorten the duration of ventilation through accelerated weaning. The literature search for additional evidence from resource-limited settings identified several investigations that could be used to grade the evidence for use in resource-limited ICUs, amounting to one randomized controlled trial [5] and eight observational studies [6-12]. Key recommendations are provided in Table 1 and more detailed information on the literature search and grading of recommendations is included in the online supplement.

Table 1 Recommendations and suggestions on ventilatory support in patients with sepsis or septic shock in resource-limited settings (with grading)

\begin{tabular}{|c|c|}
\hline ARDS diagnosis & $\begin{array}{l}\text { Use CXR and ABG in septic patients with acute respiratory failure to diagnose ARDS }(2 \mathrm{~B}) \text {; where feasible, } \\
\text { ultrasound exam of lungs and heart may be used to narrow down the diagnosis of non-cardiogenic pulmonary } \\
\text { edema (2D); oxygen pulse saturation relative to delivered oxygen concentration }(S / F) \text { may be an alternative } \\
\text { for the arterial oxygen pressure relative to delivered oxygen concentration }(P / F) \text { for decision-making and } \\
\text { continuous monitoring in settings where blood gas analyzers are absent }(2 \mathrm{D}) \text {; in patients with acute respiratory } \\
\text { failure with or without ARDS diagnosis should be managed employing the principles of lung-protective } \\
\text { mechanical ventilation (2B) }\end{array}$ \\
\hline $\begin{array}{l}\text { Semi-recumbent } \\
\text { position }\end{array}$ & $\begin{array}{l}\text { For ventilated septic patients use elevated head-of-bed ranging from } 30^{\circ} \text { to } 45^{\circ} \text { unless their hemodynamic state } \\
\text { precludes this (1B); lower patient's position to less than } 30^{\circ} \text { head-of-bed elevation transiently for the } \\
\text { necessary procedures and during the resuscitation of the shock-state until hemodynamic status is improved } \\
\text { (1B) or longer in cases of sacral decubitus ulcer (1C) }\end{array}$ \\
\hline NIV & $\begin{array}{l}\text { Use invasive mechanical ventilation in cases of severe hemodynamic disturbance (i.e., shock), and/or severe } \\
\text { hypoxemia (1A). NIV could be used in selected cases of mild respiratory failure with preserved or relatively } \\
\text { stable hemodynamic status (2A); frequent reassessments of therapeutic effect of NIV are required in order to } \\
\text { prevent delay in intubation and mechanical ventilation (1B) }\end{array}$ \\
\hline $\begin{array}{l}\text { Spontaneous breathing } \\
\text { trials }\end{array}$ & $\begin{array}{l}\text { Use spontaneous breathing trials early and regularly, preferably daily, in all ventilated patients (1A) (notably, to } \\
\text { increase the success of this strategy, excessive sedation should be prevented); use the low level of pressure } \\
\text { support technique (2D); perform spontaneous breathing trials and extubate if the trial is passed successfully } \\
\text { only at times when sufficient staff are available (2D); develop a local guideline for spontaneous breathing } \\
\text { trials (2C) }\end{array}$ \\
\hline Tidal volume size & $\begin{array}{l}\text { Use low tidal volume ventilation in patients with ARDS diagnosis (1A) and in all ventilated patients (2B) (i.e., } \\
\text { prevent tidal volumes higher than } 10 \mathrm{ml} / \mathrm{kg} \mathrm{PBW} \text {, and consider tidal volumes of } 5-7 \mathrm{ml} / \mathrm{kg} \mathrm{PBW} \text { in all } \\
\text { patients); titrate tidal volume size using PBW and not the actual body weight }(2 \mathrm{D}) \text {; timely recognize under- } \\
\text { ventilation, where respiratory rates should be adjusted (2D); accept higher respiratory rates (i.e., do not } \\
\text { increase sedation if the respiratory rate rises with the use of lower tidal volumes) (2C); end-tidal } \mathrm{CO}_{2} \\
\text { monitoring could be helpful in timely recognition of under- or overventilation (2D) }\end{array}$ \\
\hline PEEP & $\begin{array}{l}\text { Use a minimum level of PEEP }\left(5 \mathrm{~cm} \mathrm{H}_{2} \mathrm{O}\right) \text { in all patients with sepsis or septic shock with acute respiratory } \\
\text { failure (2B); consider using higher levels of PEEP only in patients with moderate or severe ARDS (2A); if } \\
\text { lack of CXR and ABG availability hampers making an ARDS diagnosis, we suggest against liberal use of } \\
\text { higher levels of PEEP (2D); when the team is trained and experienced in using respiratory dynamic } \\
\text { compliance, PEEP could be titrated based on this parameter (2D); so-called PEEP/FiO }{ }_{2} \text { tables could be used } \\
\text { for titrating PEEP, but this approach generally requires frequent ABGs (2B); patients who need higher levels } \\
\text { of PEEP are preferably closely monitored, preferably by using an arterial line, as hypotension and circulatory } \\
\text { depression may develop (1A) }\end{array}$ \\
\hline $\mathrm{FiO}_{2}$ versus PEEP & $\begin{array}{l}\text { Low } \mathrm{FiO}_{2} \text { is preferred over high } \mathrm{FiO}_{2}(2 \mathrm{~B}) \text {; the target should be } \mathrm{PaO}_{2}>8 \mathrm{kPa}(60 \mathrm{mmHg}) \text { and/or } \mathrm{SpO}_{2} 88-95 \% \\
(2 \mathrm{~A}) \text {; PEEP/FiO2 tables can be used to find the best PEEP-FiO2 combination (2B); staff with experience in } \\
\text { using PEEP could prefer to use higher levels of PEEP to treat hypoxia; in centers with little experience in } \\
\text { using PEEP, the initial response to hypoxia should be higher } \mathrm{FiO}_{2} \text { before using higher levels of PEEP (2D) }\end{array}$ \\
\hline $\begin{array}{l}\text { Recruitment } \\
\text { maneuvers }\end{array}$ & $\begin{array}{l}\text { Use recruitment maneuvers in patients with moderate or severe ARDS (2B), in patients with refractory } \\
\text { hypoxemia in whom an ARDS diagnosis cannot be made due to lack of CXR and/or ABG (2D), and only } \\
\text { when the staff are trained and experienced in performing these maneuvers (2D); use the simplest maneuver, } \\
\text { i.e., 'sustained inflation' (2D); when using recruitment maneuvers, the patient should be closely monitored, } \\
\text { preferably by using an arterial line, to promptly detect hemodynamic compromise (2B) }\end{array}$ \\
\hline Modes of ventilation & $\begin{array}{l}\text { We recommend using 'volume-controlled' modes of ventilation over 'pressure-controlled' modes of ventilation } \\
\text { (2D); we cannot recommend on whether assisted ventilation ('support' mode) is preferred over assist } \\
\text { ventilation ('controlled' mode) in all patients; use a short course of muscle paralysis }(<48 \mathrm{~h}) \text {, and thus } \\
\text { controlled ventilation, only in patients with moderate or severe ARDS (2B) }\end{array}$ \\
\hline
\end{tabular}

Grading: see online supplement for explanations

$C X R$ chest radiograph, $A B G$ arterial blood gas, $A R D S$ acute respiratory distress syndrome, $P B W$ predicted body weight, $P E E P$ positive end expiratory pressure, $N I V$ non-invasive ventilation 
In cases of strong recommendations, we use the wording 'we recommend ...'; in cases of less strong recommendations, we use the wording 'we suggest ...'.

We suggest identifying patients with ARDS diagnosis in the ICUs where this is feasible, as this may improve proper selection of additional ventilator strategies-we do recognize that this is not the case in the majority of ICUs with limited resources and therefore our overall strength of recommendation for this matter is downgraded to a suggestion; in settings where blood gas analyzers are unavailable, the $\mathrm{SpO}_{2}$ relative to delivered oxygen concentration $(S / F)$ could be used for decision-making and continuous monitoring; in the absence of chest radiography, use of ultrasound exam of lungs and heart could be helpful in narrowing down the diagnosis of non-cardiogenic pulmonary edema, where feasible; regardless of the feasibility of diagnosing ARDS, septic patients with acute respiratory failure should be managed by employing the principles of lungprotective ventilation; we recommend that the elevated head-of-bed position should be maintained in all ventilated patients to decrease the risk of aspiration; we recommend the use of invasive mechanical ventilation in cases of severe hemodynamic disturbance or severe hypoxemia, and suggest a trial of non-invasive ventilation only in patients with minor hemodynamic and oxygenation disturbances; and in these patients, we recommend close monitoring and frequent reassessments regarding the need for intubation to assure that mechanical ventilation is instituted without the delay; we suggest using a minimum level of PEEP of $5 \mathrm{~cm}$ $\mathrm{H}_{2} \mathrm{O}$ in all patients with sepsis or septic shock with acute respiratory failure, and suggest using higher levels of PEEP only in patients with moderate or severe ARDS; we suggest a preference for a low $\mathrm{FiO}_{2}$ aiming at low oxygenation goals [i.e., $8 \mathrm{kPa}(60 \mathrm{mmHg})$ and/or $\left.\mathrm{SpO}_{2}(88-95 \%)\right]$, and we suggest using $\mathrm{PEEP} / \mathrm{FiO}_{2}$ tables to find the best $\mathrm{PEEP}-\mathrm{FiO}_{2}$ combination; we suggest applying recruitment maneuvers only in patients with moderate or severe ARDS with refractory hypoxia, and only when the staff are trained and experienced in performing these maneuvers; patients who need higher levels of PEEP and recruitment maneuvers are preferably closely monitored, preferably by using an arterial line, as hypotension and circulatory depression may develop; we recommend using low tidal volumes in patients with ARDS (and to avoid tidal volumes larger than $10 \mathrm{ml} / \mathrm{kg}$ predicted body weight, and to consider tidal volumes between 5 and $7 \mathrm{ml} / \mathrm{kg}$ predicted body weight in all patients); where feasible, end-tidal $\mathrm{CO}_{2}$ monitoring could be helpful in timely recognition of dislodgement of the endotracheal tube and under- or overventilation; 'volume-controlled' modes could be safer than 'pressure-controlled' modes as minute ventilation and tidal volume size is guaranteed with volume-controlled modes; we cannot recommend a preference for 'support' modes of ventilation over 'control' modes, but do recommend checking regularly whether a patient tolerates 'support' mode; we also suggest performing spontaneous breathing trials to timely identify patients who are ready for extubation, but also to plan extubating patients when sufficient staff are around to guarantee safe re-intubation, if necessary.

\section{Conclusion}

We provide a set of simple, readily available and affordable recommendations for the 'safe' ventilatory support in patients with sepsis or septic shock in resourcelimited ICUs. Most evidence has come from resource-rich settings; therefore, there is an urgent need for related studies in resource-limited settings. Given the immense variability and range of capabilities, preparedness, and staffing of ICUs in resource-limited ICUs, each ICU practitioner will have to rationally and practically further adapt the guidelines based on their site-specific circumstances.

\section{Group members of the subgroup 'Ventilatory Support'}

Ary Serpa Neto (Hospital Israelita Albert Einstein, São Paulo, Brazil), Marcus J. Schultz (Academic Medical Center, University of Amsterdam, Amsterdam, The Netherlands \& Faculty of Tropical Medicine, Mahidol University, Bangkok, Thailand), and Emir Festic (Mayo Clinic, Jacksonville, Florida, USA), Neill K.J. Adhikari (Sunnybrook Health Sciences Centre \& University of Toronto, Toronto, ON, Canada), Arjen Dondorp (Faculty of Tropical Medicine, Mahidol University, Bangkok, Thailand \& Academic Medical Center, University of Amsterdam, Amsterdam, The Netherlands), Rajyabardhan Pattnaik (Ispat General Hospital, Rourkela, Sundargarh, Odisha, India), Luigi Pisani (University of Bari Aldo Moro, Bari, Italy), Pedro Povoa (Nova Medical School, CEDOC, New University of Lisbon, Lisbon, Portugal \& Polyvalent Intensive Care Unit, Hospital de São Francisco Xavier, Centro Hospitalar de Lisboa Ocidental, Lisbon, Portugal) and Ignacio Martin Loeches (St. James's University Hospital, Dublin, Ireland) and Louise Thwaites (Centre for Tropical Medicine and Global Health, Nuffield Department of Medicine, University of Oxford, UK). 


\section{References}

1. Dellinger RP, Levy MM, Rhodes A, Annane D, Gerlach H, Opal SM, Sevransky JE, Sprung CL, Douglas IS, Jaeschke R, Osborn TM, Nunnally ME, Townsend SR, Reinhart K, Kleinpell RM, Angus DC, Deutschman CS, Machado FR, Rubenfeld GD, Webb SA, Beale RJ, Vincent JL, Moreno R, Surviving Sepsis Campaign Guidelines Committee including the Pediatric Subgroup (2013) Surviving sepsis campaign: international guidelines for management of severe sepsis and septic shock: 2012. Crit Care Med 41:580-637

2. Dunser MW, Festic E, Dondorp A, Kissoon N, Ganbat T, Kwizera A, Haniffa R, Baker T, Schultz MJ, Global Intensive Care Working Group of European Society of Intensive Care Medicine (2012) Recommendations for sepsis management in resource-limited settings. Intensiv Care Med 38:557-574

3. Thille AW, Roche-Campo F, Brochard L (2015) Ten reasons to be more attentive to patients when setting the ventilator. Intensive Care Med. doi: 10.1007/s00134-015-3802-5

4. Global Intensive Care Working Group of European Society of Intensive Care Medicine (2013) GRADE handbook for grading quality of evidence and strength of recommendations. Updated October 2013
5. Amato MB, Barbas CS, Medeiros DM, Magaldi RB, Schettino GP, LorenziFilho G, Kairalla RA, Deheinzelin D, Munoz C, Oliveira R, Takagaki TY, Carvalho CR (1998) Effect of a protective-ventilation strategy on mortality in the acute respiratory distress syndrome. N Engl J Med 338:347-354

6. Bhadade RR, de Souza RA, Harde MJ, Khot A (2011) Clinical characteristics and outcomes of patients with acute lung injury and ARDS. J Postgrad Med 57:286-290

7. Loan HT, Parry J, Nga NT, Yen LM, Binh NT, Thuy TT, Duong NM, Campbell JI, Thwaites L, Farrar JJ, Parry CM (2012) Semi-recumbent body position fails to prevent healthcareassociated pneumonia in Vietnamese patients with severe tetanus. Trans $\mathrm{R}$ Soc Trop Med Hyg 106:90-97

8. Azevedo LC, Park M, Salluh JI, ReaNeto A, Souza-Dantas VC, Varaschin P, Oliveira MC, Tierno PF, dal-Pizzol F, Silva UV, Knibel M, Nassar AP Jr, Alves RA, Ferreira JC, Teixeira C, Rezende V, Martinez A, Luciano PM, Schettino G, Soares M, The ERICC (Epidemiology of Respiratory Insufficiency in Critical Care) investigators (2013) Clinical outcomes of patients requiring ventilatory support in Brazilian intensive care units: a multicenter, prospective, cohort study. Crit Care 17:R63
9. Serpa Neto A, Cardoso SO, Ong DS, Esposito DC, Pereira VG, Manetta JA, Slooter AJ, Cremer OL (2013) The use of the pulse oximetric saturation/ fraction of inspired oxygen ratio for risk stratification of patients with severe sepsis and septic shock. J Crit Care 28:681-686

10. Colaco AD, Nascimento ER (2014) Nursing intervention bundle for enteral nutrition in intensive care: a collective construction. Rev Esc Enferm USP 48:844-850

11. Festic E, Bansal V, Kor DJ, Gajic O, Illness USC, Injury Trials Group, Lung Injury Prevention Study I (2015) SpO2/ $\mathrm{FiO} 2$ Ratio on Hospital Admission Is an Indicator of Early Acute Respiratory Distress Syndrome Development Among Patients at Risk. J Intensive Care Med 30:209-216

12. Bilan N, Dastranji A, Ghalehgolab Behbahani A (2015) Comparison of the $\mathrm{SpO} 2 / \mathrm{FiO} 2$ ratio and the $\mathrm{PaO} 2 / \mathrm{FiO} 2$ ratio in patients with acute lung injury or acute respiratory distress syndrome. J Cardiovasc Thorac Res 7:28-31 